\title{
PENGARUH ERGONOMI DAN ANTROPOMETRI BAGI USER GUDANG BAHAN PT.MI GUNA MENINGKATKAN PRODUKTIFITAS SERTA KUALITAS KERJA
}

\author{
Heri Satria Setiawan \\ Program Studi Informatika, Universitas Indraprasta PGRI \\ heri.satria71@yahoo.com
}

\begin{abstract}
Abstrak
Faktor kenyamanan kerja dalam pekerjaan mempunyai pengaruh yang nyata dalam hal peningkatan efisiensi dan efektifitas kerja dimana peralatan dan teknologi merupakan salah satu penunjang dalam meningkatkan produktifitas pekerjaan di suatu perusahaan. Di bagian bahan seat PT.MI, para user operator selain menginput data di komputer, membuat RF(Receiving Form) juga menerima barang, meletakan barang serta mengatur pengaturan di gudang bahan, akan berdampak negatif berupa kecelakaan kerja dan penyakit yang berhubungan dengan pekerjaan. Berdasarkan pengamatan dan kuesioner yang diberikan ke operator komputer gudang, ditemukan beberapa masalah yang dapat membuat bekerja dengan tidak nyaman dan tidak natural sehingga produktivitas kerja tidak optimal. Oleh karena itu dilakukan perbaikan rancangan stasiun kerja dengan memperhatikan faktor manusia dan mesin. Antisipasi dilakukan dengan penyesuaian antara pekerja, proses kerja dan lingkungan kerja dimana pendekatan ini dikenal dengan nama ergonomi. Ergonomi memiliki arti penting bagi pekerja namun sering kali perusahaan mengesampingkan aspek ergonomi bagi pekerjanya. Kondisi kerja yang tidak memperhatikan kenyamanan, kepuasan, keselamatan dan kesehatan kerja tentunya berpengaruh terhadap produktivitas kerja. Rancangan baru dilakukan dengan mengubah kondisi tempat bekerja. Dari hasil analisis yang telah dilakukan dapat diketahui bahwa kondisi kerja baru ini lebih baik dari pada kondisi kerja sebelum redesain, misalnya ukuran fasilitas kerja yang telah disesuaikan dengan antropometri, adanya kursi kerja, meja kerja dan komputer yang ergonomi, penurunan tingkat keluhan rasa sakit pada saat bekerja, pengeluaran energi rata-rata sesudah redesain sudah lebih kecil dari sebelum redesain, Diharapkan pekerja merasa aman dan nyaman serta dapat meningkatkan produktivitas pekerja secara efisien \& efektif.
\end{abstract}

Kata Kunci : ergonomi, antropometri, produktifitas

\begin{abstract}
The Job comfort in a work is a factor having a decisive influence on the increase of efficiency and effectiveness of work in which the equipment and technology are some of supporting facilities in improving the productivity of work in a company. Besides inputting data into computers, user operators in PT.MI seat material division also make RF (Receiving Form), receive goods, put goods and make the settings in the material warehouse, bringing about negative effects such as work accidents and occupational diseases. Based on observations and questionnaires distributed to computer warehouse operators, there are some problems creating uncomfortable and unnatural working condition that lead to less optimal work productivity. Therefore, it is necessary to improve the work station design by considering human and machine factors. It is then anticipated by making an adjustment between worker, work process and work environment. It is an approach known as ergonomics. Despite its importance to the workers, the company often puts aside the ergonomics aspects for its workers. Working condition not paying attention to the job comfort, satisfaction, safety and health will certainly affect the work productivity. The new design is made by changing the condition of the workplace. The analysis results show the new working condition is better than that of before the redesigning, as seen in the size of work facilities adapted to anthropometry, the procurement of work chairs, desks and ergonomic computers, the decrease of the level of pain complaints at work, the average energy consumption that has been smaller after the redesigning. It is expected that workers can feel safe and comfortable and improve their productivity efficiently and effectively.
\end{abstract}

Key Words : Ergonomics, Anthropometry, productivity 


\section{PENDAHULUAN}

Teknologi Informasi telah berkembang menjadi alat bantu manusia dalam melaksanakan aktifitas dalam suatu perusahaan, guna bersaing dalam pasar, industri, transformasi organisasi, peningkatan jaringan bisnis, dan yang tak terlupakan juga sebagai alat untuk mempermudah tugas manusia dimana saat ini komputer sudah tidak dapat dilepaskan dari dunia bisnis dan industri modern. Manusia berhubungan dengan komputer untuk berbagai kepentingan termasuk juga ditemukan dalam penggunaan aplikasi rumah tangga sehingga teknologi harusnya membantu manusia dalam menyelesaikan suatu tugas bukannya malah membuat pemakai menjadi tidak nyaman dalam bekerja. Ergonomi diharapkan dapat memberikan peran dan solusi yang berkaitan dengan permasalahan antara pemakai dalam menggunakan komputer dalam lingkungan kerjanya berserta aspek - aspek lainnya yang terkait [1].

Selain berguna dalam mempercepat proses pekerjaan, di sisi lain ada aspek membahayakan yang meningkat, yaitu faktor kesehatan kerja. Meski kesehatan dipengaruhi banyak faktor, namun pemakaian komputer yang intens menjadi salah satu faktor penyebab gangguan kesehatan. Karakteristik gangguan kesehatan yang disebabkan oleh intensitas pemakaian komputer yang lama cenderung pada gangguan atau cidera tingkat rendah yang muncul lambat laun setelah proses salah yang lama dan berulang ketika menggunakan komputer. Walaupun muncul secara evolusif, hasil akhir dapat berupa gangguan kesehatan yang serius seperti gangguan saraf, gangguan penglihatan, cidera otot dan pergelangan, mengalami stress, dan sebagainya sehingga kami mengharapkan user menggunakan komputer secara ergonomi dengan cara nyaman duduk dan bekerja di depan komputer. Pada kenyataannya banyak pengguna yang bekerja tidak dalam posisi tubuh dan sikap kerja yang ideal.

Dalam kegiatan suatu perusahaan, kajian tentang produktivitas umumnya selalu dikaitkan hanya pada masalah teknologi produksi, metode kerja dan masalah ekonomi, padahal di samping hal tersebut yang tidak kalah pentingnya adalah masalah pengembangan sumber daya manusia dimana manusia dianggap sebagai asset perusahaan. Disini diperlukan teknik kegiatan mana yang paling relevan dan mempunyai potensi yang paling besar dalam meningkatkan produktivitas. Untuk memenangkan persaingan diperlukan adanya perbaikan sistem kerja [2]. Adapun hal-hal yang perlu diperbaiki adalah lingkungan fisik seperti pencahayaan, kelembaban dan temperatur, kebisingan, dinding serta lantai yang ada di area kerja. Prosedur kesehatan dan keselamatan kerja pun perlu diperbaiki sesuai dengan antropometri, gerakan gerakan sesuai dengan standar prinsip ekonomi gerakan. Tujuannya untuk memperbaiki sistem kerja agar lebih baik [6].

PT.MI merupakan perusahaan yang bergerak dibidang otomotif. Perusahaan ini memproduksi seat assy dan interior pesanan dari Astra, Indomobil maupun karoseri. Pesanan yang diterima dibuat dengan mengolah bahan baku/bahan mentah menjadi barang jadi sesuai pesanan. Bahan baku berupa besi, kawat, foam, leather, cat, dan lain - lain yang di pasok oleh beberapa vendor. Bahan baku ini diterima di bagian gudang bahan seat dan gudang bahan interior dimana terdapat user yang melakukan penginputan data, penerimaan barang/masuk gudang, penerbitan RF dimana selain input data mereka juga menerima berkas dan barang, print, memberikan tanda bukti dan bahkan menerima bahan baku tersebut. Cara kerja user ini tentunya sangat berpengaruh terhadap unsur kesehatan dan keselamatan 
kerja dan tentunya juga berpengaruh terhadap tingkat produktifitas.

Permasalahan yang dihadapi adalah sistem kerja yang kurang baik.misal cara kerja pengguna berupa gerakan-gerakan kerja tidak memenuhi standar prinsip ekonomi gerakan, beban kerja yang berlebih dsb, lingkungan fisik yang ada seperti pencahayaan serta sirkulasi udara yang kurang di ruangan gudang, lembab, kebisingan dan lantai gudang yang licin, fasilitas fisik kurang baik, serta sistem kesehatan dan keselamatan kerja (K3) yang kurang baik berupa sering terjadinya kecelakaan kerja, upaya pencegahan dan upaya penanggulangan yang dilakukan perusahaan belum efektif, Terdapat banyak sekali aspek ergonomi yang dapat mempengaruhi tingkat produktivitas pekerja, seperti Usia, Keterampilan dan Pengalaman Kerja, Cara Kerja, Motivasi Kerja, Kelelahan Kerja dll.

Adapun tujuan dan manfaat penelitian untuk perbaikan kondisi dan lingkungan kerja di PT.MI guna meningkatkan produktifitas perusahaan, pekerja dapat bekerja secara efisien dan efektif, tingkat kecelakaan kerja yang berkurang, serta penerapan 5S sekaligus pembelajaran bagi perusahaan maupun akademisi. Penelitian inipun masih membutuhkan masukan dari pihak manajemen perusahaan maupun para akademisi demi penyempurnaan selanjutnya.

\section{METODE PENELITIAN}

Objek dari penelitian ini adalah user/operator komputer di gudang bahan baku PT.MI. Penelitian ini dilakukan mengingat aspek ergonomik merupakan salah satu aspek yang menunjang untuk menciptakan kesehatan dan keselamatan kerja yang baik di lingkungan perusahaan guna meningkatkan produktifias. Salah satu cara untuk meningkatkan produktifitas yaitu melalui ergonomi, berfungsi pula untuk menghemat biaya dalam perusahaan dan meningkatkan pefisiensi dan efektifitas kerja. Tujuan ergonomi dan K3 hampir sama yaitu untuk menciptakan kesehatan dan keselamatan kerja, namun kenyataannya penerapan ergonomi dan K3 di perusahaan terutama di perusahaan kecil dan menengah masih jauh dari yang diharapkan. Program-program ergonomi dan K3 sering menempati prioritas yang rendah dan terakhir bagi manajemen perusahaan [6].

Metode ergonomik meliputi diagnosis, dapat dilakukan melalui wawancara dengan pekerja, inspeksi tempat kerja, penilaian fisik pekerja, uji pencahayaan, pengukuran lingkungan kerja. Ada beberapa pendekatan seharusnya digunakan :

a. Wawancara karyawan tentang pekerjaan yang mereka lakukan, setiap permasalahan yang mereka punyai, dan dampaknya terhadap kesehatan, keselamatan, dan kinerja

b. Penilaian sistem kerja seperti peralatan yang digunakan, pengaturan kerja, kesalahan kerja

c. Pengujian insiden kerja menggunakan laporan kecelakaan untuk mengidentifikasi rincian peristiwa dan kemungkinan penyebabnya, absensi ketidakhadiran, tingkat perpindahan staf.

Juga dengan memperhatikan posisi cara kerja user, ada yang saat telpon dijepit dileher, kelamaan input data, merokok sambil bekerja, kipas angin mengarah langsung ke pekerja dll. Perangkat kerja yang dapat disetel sesuai postur orang Indonesia seperti kursi setel, meja dll.

Treathment, dapat dilakukan dengan cara perubahan posisi meubel, letak pencahayaan dan sistem sirkulasi udara yang baik. Follow up, dilakukan dengan menanyakan kenyamanan, sifat kerja, keletihan, sakit akibat posisi kerja, tingkat stress. Untuk fasilitas fisik yang diamati 
meliputi kursi, meja, rak, perangkat komputer. Selanjutnya dilakukan analisis terhadap lingkungan fisik ( temperatur dan kelembaban, pencahayaan, tingkat kebisingan).

Tahapan Penelitian

Tahap 1. Melakukan diagnosis dengan mengobservasi langsung terhadap penerapan aspek ergonomi di lingkungan kerja PT.MI. Pengumpulan data dilakukan secara langsung pada stasiun kerja yaitu gudang bahan untuk mengetahui kondisi kerja, dilakukan pengambilan gambar terhadap stasiun kerja, pengambilan / pengumpulan ukuran stasiun kerja, dimensi tubuh manusia, catatan kecelakaan kerja, hasil target kerja.

Tahap 2. Pada tahap ini dilakukan proses wawancara kepada pekerja untuk menyelesaikan masalah terkait dengan ergonomi. Pengumpulan data ialah dengan cara wawancara terhadap pekerja baik itu pekerja di gudang bahan seat maupun di gudang bahan interior atas keluhankeluhan mereka terhadap kondisi fisik lingkungan kerja khususnya serta observasi langsung Langkah-langkah yang dilakukan adalah:

a. Identifikasi keluhan.

Pada tahap ini karyawan yang bekerja di gudang diwawancarai mengenai keluhan yang dirasakan terhadap kondisi sistem kerja terkait dengan aspek ergonomi.

b. Rancangan perbaikan.

Pada tahap ini karyawan dimintai tanggapan untuk menentukan desain perbaikan mengenai tata ulang sistem.

c. Menerapkan rancangan perbaikan.

Pada langkah ini dilakukan penerapan rancangan perbaikan yang telah disetujui oleh pihak yang terkait.

Tahap 3. Melakukan perbaikan (treatment) Obyek penelitian ini akan dilakukan perancangan ulang (redesign) stasiun kerja dengan kondisi yang dapat menunjang peningkatan kerja dari operatornya. Karena dengan kondisi kerja aman, nyaman, tentram dan menyenangkan, manusia sebagai pekerja akan mencapai produktivitas yang tinggi serta dapat bertahan dalam jangka waktu yang lama. Berdasarkan uraian tersebut, maka kami menerapkan ergonomi dengan analisis ergonomi terhadap stasiun kerja dengan antropometri orang Indonesia pada umumnya serta cara kerja/sikap kerja, agar operator bisa bekerja dengan efektif, nyaman, aman, sehat dan efisien.

Tahap 4. Melakukan wawancara dan penyebaran kuesioner, sebelum dan sesudah perubahan. Follow Up dilakukan dengan cara menanyakan kenyamanan, bagian badan yang sakit, nyeri bahu dan siku, keletihan, sakit kepala dan lain-lain setelah dilakukan perubahan posisi meubel, membeli furniture yang sesuai dengan dimensi fisik pekerja, letak pencahayaan atau jendela yang sesuai. Bagian untuk pencahayaan dan sirkulasi udara setidaknya 1/6 dari dinding ruangan.

Perbaikan dilakukan secara terus menerus demi meningkatkan kualitas kerja dan tingkat kesehatan terhadap karyawan.

\section{HASIL DAN PEMBAHASAN}

Variabel penelitian dalam penelitian ini adalah variabel bebas dan terikat. Variabel bebas bertindak sebagai masukan penelitian yaitu perbaikan sistem kerja. Sedangkan variabel terikat adalah efektivitas kerja dan produktivitas karyawan yang bertindak sebagai keluaran yang diukur. Hasil masukan dari lapangan diperoleh tataletak ruang kerja, perangkat kerja serta cara kerja yang kurang baik sehingga mempengaruhi kenyamanan dalam bekerja.

Dalam perancangan stasiun kerja, aspek awal yang harus diperhatikan adalah yang menyangkut perbaikan-perbaikan metode atau cara kerja dengan menekankan pada prinsip-prinsip ekonomi gerakan dengan tujuan pokoknya adalah meningkatkan efisiensi dan produktivitas kerja. Aspek kedua yang menjadi pertimbangan adalah 
kebutuhan akan data yang menyangkut dimensi tubuh manusia (anthropometric data). Data antropometri ini terutama sekali akan menunjang didalam proses perancangan produk dengan tujuan untuk mencari keserasian hubungan antara produk dan manusia yang memakainya. Aspek ketiga yang perlu dipertimbangkan berikutnya adalah berkaitan dengan pengaturan tata letak fasilitas kerja yang diperlukan dalam suatu kegiatan [3]. Pengaturan fasilitas kerja pada prinsipnya bertujuan untuk mencari gerakan-gerakan kerja yang efisien. Dalam perancangan atau redesain stasiun kerja itu sendiri harus diperhatikan peranan dan fungsi pokok dari komponen-komponen sistem kerja yang terlibat yaitu manusia, mesin/peralatan dan lingkungan fisik kerja [4]. Aspek berikutnya berhubungan dengan masalah keselamatan dan kesehatan kerja. hubungan dan perilaku manusia, pengukuran waktu kerja, tingkat stres dan maintanability akan berkepentingan dengan memperbaiki motivasi dan performan kerja.

Yang dianalisa adalah :

a. Beban kerja dan tuntutan pekerjaan. Hasilnya operator komputer selain bertugas sebagai data entry, juga membuat RF, menerima barang

b. Peralatan yang digunakan kurang memadai seperti layar monitor CRT, saklar listrik yg dipakai beramai-ramai peralatan lain, printer yang letaknya terlalu tinggi yaitu di rak.

c. Lingkungan fisik (Suhu, kelembaban, pencahayaan, kebisingan, getaran) dan lingkungan sosial (seperti kerjasama tim dan manajemen yang mendukung).

d. Terdapat pekerja dengan ukuran dan bentuk tubuh yang tidak standar sehingga perlu penanganan khusus

e. Postur tubuh saat bekerja yang terkadang menginput data komputer sambil berdiri f. Faktor indera terutama pada operatror yang telah berusia diatas 40 tahun, perlu kacamata dan pencahayaan yang cukup

g. Ketegangan pada otot akibat membantu mengangkat barang, keringat, detak jantung melebihi normalnya 90-110 kali/menit.

h. Seragam kerja para karyawan.

i. Konsumsi energi yang berlebihan dll.

Secara umum lingkungan fisik terbagi dalam dua kategori, yaitu lingkungan yang langsung berhubungan dengan pekerja tersebut seperti stasiun kerja, kursi, meja dsb. Kedua, lingkungan perantara atau lingkungan umum contohnya sirkulasi udara, temperatur, kelembaban, pencahayan, kebisingan, getaran mekanis, bau-bauan bahan kimia dll.

Fasilitas fisik di gudang mencakup:

a. Penempatan layar yang kurang baik, ada yang terlalu tinggi, terlalu rendah, jauh dari jangkauan tangan pekerja. Layar silau akibat pantulan lampu dan cahaya dari jendela. Perangkat Keras, layar monitor masih berupa tabung CRT tidak cocok untuk tugas atau orang yang menggunakannya sehingga menyebabkan bahaya radiasi.

b. Mouse kadang tertutup oleh tumpukan berkas - berkas dan kabel mouse yang sering nyangkut map yang berantakan.

c. Pesawat telephone yang digantung di dinding

d. Kursi yang tidak memberikan kenyamanan bagi pekerja karena banyak yang sudah rusak.

e. Meja yang digunakan berukuran panjang $150 \mathrm{~cm}$, lebar $60 \mathrm{~cm}$, tinggi 95 cm. Sempit.

f. Rak, panjang $150 \mathrm{~cm}$, lebar $50 \mathrm{~cm}$, tinggi $250 \mathrm{~cm}$. Rak penuh bahkan sampai atas rak.

g. Suara kipas angin

h. Terdapat rak kabinet yang berkarat.

i. Tidak cukup ruang lega untuk bekerja. 
j. Tidak cukup waktu untuk beristirahat atau perubahan-perubahan dari aktivitas.

k. Tugas atau pekerjaan dilaksanakan di bawah tekanan waktu dan terlalu sedikit waktu untuk beristirahat. Pekerjaan input data dilakukan saat lembur dikarenakan membantu rekan kerja bagian gudang yang kewalahan.

Hasil pengukuran lingkungan fisik gudang bahan seat assy:

a. Temperatur suhu dan kelembaban

Pada pagi hari berkisar antara $26^{\circ} \mathrm{C}-$ $28^{\circ} \mathrm{C}$. Siang siang hari berkisar antara $30^{\circ} \mathrm{C}-32.5^{\circ} \mathrm{C}$ dan pada sore hari berkisar antara $28^{\circ} \mathrm{C}$. $-30^{\circ} \mathrm{C}$. Panas (ideal $24-27^{\circ} \mathrm{C}$ ). Kualitas udara kurang baik. Kelembaban pada pagi hari berkisar antara $32 \%-33 \%$. Siang hari berkisar antara 33\% $-34 \%$ dan pada sore hari berkisar antara 33-36 \%. Kering (Ideal 60-70\%)

b. Pencahayaan

Pada pagi hari berkisar antara 78- 85 lux. Siang hari berkisar antara 85-99 lux dan pada sore hari berkisar antara 75-90 lux. Kurang terang (Ideal 300-500 lux)

c. Kebisingan, gangguan suara

Pada pagi hari berkisar antara 68-72 dB. Siang hari berkisar antara 70-72 dB dan pada sore hari berkisar antara 71-73 dB. Bising (tenang $40 \mathrm{~dB}$ )

d. Ruang kerja yang kotor, banyak sampah.

Hasil pegukuran lingkungan fisik untuk gudang bahan interior:

a. Temperatur suhu dan kelembaban

Pada pagi hari berkisar antara $26^{\circ} \mathrm{C}-$ $27^{\circ} \mathrm{C}$. Siang siang hari berkisar antara $30^{\circ} \mathrm{C}-31.5^{\circ} \mathrm{C}$ dan pada sore hari berkisar antara $27^{\circ} \mathrm{C}-29^{\circ} \mathrm{C}$. Panas (Ideal $24-27^{\circ} \mathrm{C}$ ). Polusi. Kelembaban pada pagi hari berkisar antara $27 \%-34$ $\%$. Siang hari berkisar antara $27 \%-34$ $\%$ dan pada sore hari berkisar antara 31 $\%-34 \%$. Kering (Ideal 60-70\%). b. Pencahayaan

Pada pagi hari berkisar antara 61- 75 lux. Siang hari berkisar antara 63-75 lux dan pada sore hari berkisar antara 65-75 lux. Kurang terang (Ideal 300-500 lux)

c. Kebisingan, kegaduhan

Pada pagi hari berkisar antara 56-60 dB. Siang hari berkisar antara 60-66 dB dan pada sore hari berkisar antara 56-62 dB.Bising (tenang 40dB)

d. Kadang terjadi getaran karena terletak dekat ruang produksi.

Kebiasaan dalam bekerja

a. Masih banyak pengguna komputer yang bekerja dengan posisi yang tidak benar.

b. Pengaturan hari kerja, jam kerja yang kurang baik.

c. Waktu pemulihan yang tidak cukup antara shift.

d. Penjadwalan shift yang kurang sesuai.

e. Karyawan bekerja melebihi jam kerja normal.

f. Kemampuan mental, beban kerja berlebih.

g. Ada seseorang yang mudah marah, tersinggung.

h. Ada beberapa PHL (Pekerja Harian Lepas) yang belum ahli dalam pekerjaannya, pengetahuan penggunaan komputer yang masih minim.

Secara ideal perancangan stasiun kerja haruslah disesuaikan peranan dan fungsi pokok dari komponen-komponen sistem kerja yang terlibat yaitu manusia, komputer/peralatan dan lingkungan fisik kerja. Peranan manusia dalam hal ini akan didasarkan pada kemampuan dan keterbatasannya terutama yang berkaitan dengan aspek pengamatan, kognitif, fisik ataupun psikologisnya. Demikian juga peranan atau fungsi komputer/peralatan seharusnya ikut menunjang manusia (operator) dalam melaksanakan tugas yang ditentukan. Dalam kaitannya dengan lingkungan fisik kerja seringkali dijumpai bahwa perencana sistem kerja justru lebih memperhatikan komputer/peralatan yang 
harus lebih dilindungi dari pada melihat kepentingan manusia-pekerjanya [7].

Berkaitan dengan perancangan areal/stasiun kerja dalam industri, maka ada beberapa aspek ergonomis yang harus dipertimbangkan sebagai berikut :

a. Sikap dan posisi kerja.

b. Antropometri dan dimensi ruang kerja.

c.Efisiensi ekonomi gerakan dan pengaturan fasilitas kerja.

Berdasarkan hasil analisis diketahui ada hal-hal yang tidak ergonomis. Para operator dalam melakukan pekerjaannya, posisi kerja mereka tidak sesuai dengan prinsip-prinsip ergonomi yaitu terlalu membungkuk, jangkauan tangan yang tidak normal, perangkat komputer yang tidak bekerja dengan baik, tombol keyboard copot, kondisi meja dan bangku yang tidak ergonomis. Sehingga dari posisi kerja operator tersebut dapat mengakibatkan timbulnya berbagai permasalahan yaitu kelelahan dan rasa nyeri pada punggung akibat dari duduk yang tidak ergonomis tersebut, timbulnya rasa nyeri pada bahu dan kaki akibat ketidak sesuaian antara pekerja dan lingkungan kerjanya. Kondisi yang tidak dikehendaki misalnya menyangkut tangan yang melebihi tinggi siku, terlalu rendahnya kursi, posisi membungkuk, jarak jangkauan yang terlalu jauh atau terlalu dekat, kondisi seperti ini akan berpengaruh pada pekerja misalnya rasa nyeri pada punggung, rasa nyeri pada lengan, untuk mengetahui hal tersebut dilakukan analisa physiological performance. Untuk memperoleh kesesuaian antara stasiun kerja dengan segmen tubuh penggunanya maka dilakukan perancangan ulang terhadap dimensi stasiun kerja yang tidak ergonomis tersebut.

Keadaan lingkungan fisik yang disarankan yang mencakup: a. Pencahayaan

Dari kondisi pencahayaan yang ada ,pencahayaan kurang optimal perlu tambahan neon, gunakan cahaya tidak langsung (300 - 500 lux ).

b. Kelembaban

Kelembaban yang ada bersifat kering sehingga perlu diusulkan adanya humidifier yang digunakan untuk menjaga kelembapan suhu. Perlu dibuka jendela dan pintu.

c. Kebisingan

Pasang peredam dan jauhi dari pusat kebisingan

d. Dinding Produksi

Kondisi dinding sudah pudar sehingga perlu diusulkan untuk pengecatan ulang warna terang

e. Lantai

Lantai dicat dengan cat minyak sehingga agak licin, perlu perhatian bagi pekerja agar tidak terpeleset.

f. Atap Ruangan Produksi

Ketinggian atap ruangan produksi di perusahaan yaitu $4 \mathrm{~m}$. dan kotor. Untuk itu perlu dilakukan pembersihan dan penambahan exhaust fan agar lebih adem.

g. Perbaikan grounding

h. Perlu Ruang khusus penyimpanan bahan kimia berbahaya

i. Perbaikan sarana dan prasarana seperti perbaikan kursi, perangkat komputer

Saran kepada pihak perusahaan yaitu sebagai berikut :

Karena lingkungan fisik dari perusahaan ini bermasalah terhadap pencahayaan, kelembapan, ventilasi, kebisingan, warna dinding produksi,lantai produksi dan atap produksi sebaiknya perusahaan menambah jumlah lampu, ganti bohlam dengan neon/LED, menambah humidifier pada lingkungan produksi, menambah exhaust fan, melakukan pengecatan pada dinding produksi, mengganti atap produksi yang sudah kotor, arah kipas angin jangan ke pekerja. 
Menyediakan kursi ergonomi yang tingginya bisa disesuaikan, memindahkan benda-benda yang berada dibawah meja untuk menciptakan ruang yang cukup untuk kaki.

Memberikan seragam kerja karyawan dengan bahan yang nyaman.

Membatasi jam lembur dan merubah pola kerja bergilir.

Sistem kesehatan dan keselamatan kerja pada perusahaan ini belum baik, terlihat dari banyak kecelakaan kerja yang ada,upaya pencegahan dan penanggulangan perusahaan yang masih belum efektif. Perlu peningkatan K3, pemakaian masker bila polusi, earpug jika bising.

Pastikan bahwa segala perubahan dievaluasi dengan baik oleh para pekerja yang melakukan pekerjaannya. Berhatihatilah bahwa sebuah perubahan untuk memecahkan sebuah masalah tidak diciptakan untuk menimbulkan masalah baru.

Cara berkomputer yang baik dengan mengurangi kemungkinan kelelahan dan ketidaknyamanan yaitu dengan mengikuti aturan 20/20 yaitu setiap 20 menit bekerja, break selama 20 detik dan alihkan padangan ke jarak jauh. Jangan lupa sering kedipkan mata saat memandang komputer. Atur meja bagaimana perangkat digunakan dengan mempertimbangkan bagaimana perangkat digunakan, atur pencahayaan. Gunakanlah prinsip-prinsip menggunakan komputer secara sehat, baik dan benar.

\section{Simpulan}

\section{SIMPULAN}

Telah diperbaiki tata letak ruang kerja yang sesuai dengan ilmu ergonomi. Ruang kerja dimaksud harus memberi kenyamanan pada para pekerjanya. Hal ini dapat dicapai antara lain dengan memperhatikan tata letak ruang kerja tersebut dalam melaksanakan tugasnya berdasarkan ukuran dimensi peralatan/perlengkapan, dimensi ruang kerja serta jarak bebas antar peralatan yang ditetapkan. Ergonomi yang bersasaran akhir efisiensi dan keserasian kerja memiliki arti penting bagi tenaga kerja, baik sebagai subyek maupun obyek.

\section{Saran}

Manajemen harus memperhatikan pendekatan desain melalui penelaahan standar dan aturan ergonomi serta terus memantau perkembangan yang ada. Kepada para pekerja hendaknya memperhatikan posisi tubuh saat bekerja agar tidak terjadi cedera yang berdampak buruk bagi kesehatan nantinya, pakai masker dan earplug. Perlu dilakukan penyuluhan kepada pekerja mengenai bahaya yang timbul akibat posisi yang salah saat bekerja.

\section{DAFTAR PUSTAKA}

[1] Nurmianto, Eko. Ergonomi Konsep Dasar dan Aplikasinya. Edisi Pertama. Jakarta: Guna Widya. 2003.

[2] Manuaba A. Pengaruh Ergonomi Terhadap Produktifitas. Bunga Rampai Ergonomi Vol 1. Denpasar: PS Ergonomi Fisiologi Kerja Universitas Udayana. 1992.

[3] Purnomo, H. Antropometri dan Aplikasinya. Yogyakarta: Graha Ilmu. 2012.

[4] Santoso, Gempur. Ergonomi Manusia, Peralatan dan Lingkungan. Jakarta: Prestasi Pustaka. 2004.

[5] Suma'mur. Ergonomi Untuk Produktivitas Kerja. Jakarta : PT Temprint. 1989.

[6] Tarwaka, Solichul H, A. Bakri dan Sudiajeng,. Ergonomi untuk Keselamatan, Kesehatan Kerja dan Produktifitas. Surabaya: UNISBA PRESS. 2004.

[7] Tim Ergoinstitute. Kisah Sukses Penerapan Ergonomi. Bandung: Ergo News. Edisi 3. Juni 2008. 